\title{
Study of the Effect of "Qigong" on the Functional State of Cardiorespiratory System of School Children
}

\author{
Tarabrina N.Yu. \\ Department of Physical Education \\ Moscow Aviation Institute (National Research University) \\ Moscow, Russia \\ nata-tarabrina@mail.ru
}

\author{
Kraev Yu.V. \\ Department of Physical Education \\ Moscow Aviation Institute (National Research University) \\ Moscow, Russia \\ yury.kraev@mail.ru
}

\author{
Tikhonov A.I. \\ Department of Personnel Management \\ Moscow Aviation Institute (National Research University) \\ Moscow, Russia \\ mai512hr@mail.ru
}

\begin{abstract}
The development of new effective methods of physical education of junior schoolchildren and search of combinations of instruments and methods of training, contributing to the increase interest to physical education lessons, activation of motor activity in the lesson, the integrated development of motor skills and the increase of the level of functionality of the leading systems of the body is an actual interdisciplinary problem. The aim of this work was to study the influence of "Qigong" on the functional state of the cardiorespiratory system of schoolchildren. In the period 20162017, 34 children of 10-12 years of age were examined; they were divided into two groups: the control group consisted of 10 pupils engaged in physical education according to the school program. The main group consisted of 24 pupils of the same age in addition to physical education practiced for one year three times a week for two academic hours Taoist gymnastics "Qigong" by the method of the school "Dragon-Tiger" of Lun-Hu-Chuan. The study was conducted during the academic year (four steps). In both groups at each step it was studied the indicators of the cardiohemodynamics and spirometry. It is shown that there is an increase in the intensity of the influence of the autonomic nervous system on systemic circulation of the children from the main group and there is a decrease in metabolic and humoral effects on the heart. In the control group, the changes were mainly related to the vascular system and less in cardiac activity.
\end{abstract}

Keywords-Qigong; cardiovascular system; respiratory system; schoolchildren.

\section{INTRODUCTION}

Annual official reports about health of the people of the Russian Federation state the health deterioration of schoolchildren $[1,2]$. The solution of disharmonious physical development is seen in physical education, the purpose of which is to increase motor activity and to improve health in general. Various physical readiness is based on a high level of development of the basic motor qualities (endurance, strength, agility, speed, etc.), which are achieved by systematic work in physical education lessons, as well as in the process of afterhour sports and activities [3,4,5,6,7].

Spiritual and physical practices of the East play an important role in the structure of these activities $[4,8,9,10]$. "Qigong" occupies a special place among all Chinese healthimproving gymnastic complexes. "Qigong" is a kind of psychophysical training ("Gong" means work) to improve our feelings ("Qi"). According to ancient Eastern philosophers, the energy of "Qi" flows through the channels of the human body, which are called meridians. Channels and branches form a closed system that permeates all parts of the human body. Classical channels are connected with internal organs and the functioning of organs and tissues depends on the state of these meridians, conducting the energy of "Qi" $[8,9,10]$.

Greten's H. J. (2012-2014) studies indicate that we can see significant changes in parameters such as blood pressure, heart rate and heart rate variability, reduction of plasma triglycerides, total cholesterol and low-density lipoprotein cholesterol, skin temperature and improvement of lung functions (increased forced expiratory volume, etc.) during Qigong" lessons. [8,9,11].

Famous Chinese doctors such as Ge Hong, Tao Hongjing, Chao Yangfan, Sun Simiao, Lee Schicai, Wang An, Shen Csiniao etc. in their papers turned the classical canons of medical thought in Ancient China and also described the different methods of traditional Taoist breathing exercises [12]. According to these authors, in comparison with other medical means, respiratory gymnastics possesses a number of very essential advantages: during treatment, needles and medicines are not used, so it is very convenient and economic $[3,11,12,13]$. It is very important that the treatment using breathing exercises is completely painless. 
The positive effect of gymnastics "Qigong" in the system of correction of the functional state of the person is studied right good [13,14,15]. Most studies evaluating the effect of "Qigong" for health was conducted among middle-aged people and older generation. A number of studies have shown that this technique reduces pain, increases the range of motion in the joints, improves proprioception, mental health and wellbeing and boosts both cardiovascular and respiratory function with few adverse side effects. Qigong methods are different for young people compared to adults, so, the effectiveness of the practice is not the same [12]. Therefore, the aim of the work is to study the influence of "Qigong" classes on the functional state of the cardiorespiratory system of schoolchildren. We need to analyze the feasibility and justify the possibility of using "Qigong" in the system of school physical education.

\section{MATERIAL AND METHODS}

\section{A. Participants}

The research was conducted on the basis of the secondary school of Perevalnoye village in Simferopol district, Republic of Crimea, Russia. 34 children of the age of 10-12 years were examined. They were divided into two groups: the first one consisted of 10 pupils engaged in physical education according to the school program. The second one (main group) consisted of 24 pupils of the same age in addition to physical education practiced for one year three times a week for two academic hours Taoist gymnastics "Qigong" by the method of the school "Dragon-Tiger" of Lun-Hu-Chuan.

\section{B. Study design}

Practical classes of "Qigong" were held three times a week during two academic hours, consisted of warm-up exercises, joint exercises, breathing and relaxation exercises, exercises for the development of stability, self-massage, static forms of exercise and dynamic "Qigong" with the style "animals", among others. The study was conducted in four steps: step I started in the beginning of the school year, step II started three months later, step III started in six months, IV round started at the end of the school year.

Changes in the functional parameters of the respiratory system were registered using the medical diagnostic complex «SPHERE-4» (Ukraine) in a sitting position [16]. During the survey the person was performing three breathing tests: normal breathing for the definition of a measure respiratory rate (RR); the trial, which determines respiratory volume (RV) and the trial that determines the vital capacity of the lungs (VC). And first static (quiet) maneuvers (normal breathing, measurement RV) were performed prior to forced ones (the trial that determines the $\mathrm{VC}$ ). After all of the breathing maneuvers, the results were reduced to a table named "Design matrix", which also calculated the index of contingency of cardio-respiratory system work, known as the Hildebrante Index (HI)

Anthropometry parameters and a number of indicators reflecting the functional state of central hemodynamics were recorded in all subjects [14]. Heart rate was determined by palpation on the carotid artery (in the area of the sinus caroticus). Blood pressure was measured at the state of rest, while sitting, according to the standard method (indirect method of Korotkov). Systolic and diastolic blood pressure was recorded. Then the following parameters were calculated: vegetative Kedro index (VKI) as an indicator of the predominance of tone of autonomic nervous system (ANS), as well as the adaptive potential (AP), reflecting the severity of adaptive reactions, due to the development of functional reserves of the body [16]

\section{Statistical analysis}

Calculations and graphic design of the data obtained in the work were carried out using Microsoft Excel and the program package "STATISTICA - 10.0". The selection of the criterion for testing statistical hypotheses and measures of central trends used to describe the data was carried out depending on the results of the distribution test, which was completed using the Shapiro-Wilk criterion. To test the null hypothesis about the absence of differences in the associated groups with a normally distributed sign, the procedures of one-factor analysis of variance of repeated observations (Repeated Measures ANOVA) were used at first. Then the normality of the distribution of the difference between the values of the trait for the paired student test and the sphericity condition for the variance analysis of repeated observations were checked. Then, in cases of acceptance of an alternative statistical hypothesis, a pair comparison of groups was carried out using the parametric Student test. In this case, the arithmetic mean (M) was used as a measure of the central tendency, and the standard error of the arithmetic mean (m) was used as a scattering measure.

\section{RESULTS}

The results of the studies indicate that at the beginning of the experiment (step I) the heart rate of the children of the main group was within the age physiological norm (table 1).

However, it should be noted that all children tended to tachycardia, because a heart rate in the study group was $98.71 \pm 8.0$ beats/min. Indicators of APs are $115,2 \pm 5,0 \mathrm{~mm} \mathrm{Hg}$ and indicators of APd are $85,32 \pm 8,0 \mathrm{~mm} \mathrm{Hg}$, which is also rather more than normal. The VKI was equal to $0,86 \pm 0,05$ conv. un., this number indicates the predominance of sympathetic tone regulation of the nervous system [14]. The AP was within normal limits and corresponded to $2,18 \pm 0,14$ conv. un. (table 1).

At the second step (after three months of Taoist gymnastics "Qigong") some of the recorded indicators changed. Therefore, the heart rate decreased by 7,13\% (p $<0,01$ ), APs by $4,46 \%$ ( $p<0,05)$. APd decreased significantly by $10,24 \%(\mathrm{p}<0,01)$. These changes resulted in a slight but significant displacement of the vegetation index in the direction of normalization of the tonus of the ANS, VKI changed by $2,32 \%(\mathrm{p}<0,05)$ and became equal to $0,84 \pm 0,03$ conv. un. Along with these changes, the AP has improved by $5,50 \%(\mathrm{p}<0,05)($ table 1 , table 2). 
VKI declined by $6,97 \%(\mathrm{p}<0,001)$ in the direction of parasympathicotonia and became equal to $0,92 \pm 0$, conv. un., what led to the normalization of the ANS tone.

With regard to the control group of the children, it should be noted that the changes that were observed during the year were mainly related to the vascular system and less to the changes in cardiac activity (table 3 ).

So, four indicators changed significantly: APs decreased by $4,67 \%(p<0,01)$, heart rate decreased by $2,58 \%(p<0,05)$, VKI decreased by $1,09 \%(\mathrm{p}<0,05)$, AP decreased by $1,26 \%$ $(\mathrm{p}<0,05)$.

By comparing the changes in the relative indicators $(\%)$ of children in the control and the main groups, it was revealed that there were significant changes in the main cardiovascular indicators.

As shown in the tables 1,2. after the first six months of the training, i.e. at the third step, three of the five registered indicators in the main group were changed. So, heart rate was changed significantly in the direction of normotony and began to correspond to 84,96 beats/min. These changes amounted to $6,08 \%(\mathrm{p}<0,001)$. This indicates parasympathetic effects on the part of the ANS, which is confirmed by the level of VKI equal to $0,9 \pm 0,03$ conv. un. It increased a little bit in comparison with the second step by $7,56 \%(\mathrm{p}<0,01)$ and AP decreased by $3.88 \%(p<0,05)$ and became equals to $1,98 \pm 0,24$ conv. un

TABLE II. CHANGES IN HEMODYNAMIC PARAMETERS OF THE CHILDREN OF THE MAIN GROUP $(\mathrm{N}=24)$ AT ALL STEPS OF RESEARCH DURING THE CALENDAR YEAR $(\mathrm{M} \pm \mathrm{M})$

\begin{tabular}{|c|c|c|c|c|}
\hline Indicators & $\begin{array}{c}\Delta \% \\
\text { (Steps I-II) }\end{array}$ & $\begin{array}{c}\Delta \% \\
\text { (Steps II- } \\
\text { III) }\end{array}$ & $\begin{array}{c}\Delta \% \\
\text { (Steps III- } \\
\text { IV) }\end{array}$ & $\begin{array}{c}\Delta \% \\
\text { (Steps I-IV) }\end{array}$ \\
\hline $\begin{array}{l}\text { Aps } \\
(\mathrm{mm} \mathrm{Hg})\end{array}$ & $-4,46^{*}$ & $-0,90$ & $-1,53$ & $-6,76$ \\
\hline $\begin{array}{l}\text { APd } \\
(\mathrm{mm} \mathrm{Hg})\end{array}$ & $-10,24 * *$ & $-0,92$ & $-4,27 *$ & $-13,12^{*}$ \\
\hline $\begin{array}{l}\text { Heart rate } \\
\left(\min ^{-1}\right)\end{array}$ & $-7,13 * *$ & $\begin{array}{l}-6,08 \\
* * *\end{array}$ & $-4,74 * *$ & $-17,86^{* * *} *$ \\
\hline $\begin{array}{l}\text { AP } \\
\text { (conv.un.) }\end{array}$ & $-5,50 *$ & $-3,88^{*}$ & $\begin{array}{c}-5,88 \\
* *\end{array}$ & $-14,22 * * *$ \\
\hline $\begin{array}{l}\text { VKI (conv. } \\
\text { un) }\end{array}$ & $-2,32 *$ & $7,56^{*}$ & 2,0 & $-6,97 * * *$ \\
\hline
\end{tabular}

As shown in the tables 1 and 2, the greatest changes occurred after one year of lessons, that is, at the step IV. Four of the five indicators registered significant changes.

So, the APd decreased by $13,12 \%(\mathrm{p}<0,05)$ and became equal to $74,12 \pm 5,74 \mathrm{~mm} \mathrm{Hg}$, the heart rate decreased by $17,86 \%(\mathrm{p}<0,001)$ and became equal to $81,08 \pm 9,02$ beats $/ \mathrm{min}$ and the AP rate decreased by $14,22 \%(\mathrm{p}<0,001)$, what is the physiological norm.

It is known that the decrease in heart rate (negative chronotropic effect) reduces the need for myocardium in oxygen, due to a decrease in the magnitude of its work, and also increases diastole [17]. Bradycardia occurs as a result of changes in the levels of neurovegetative regulation at epy state of rest, when, along with an increase in the tone of the parasympathetic nervous system, the activity of the sympathetic-adrenal system decreases [16].
TABLE III. CHANGES IN HEMODYNAMIC PARAMETERS IN CONTROL GROUP OF THE CHILDREN (N=10) AT ALL STEPS OF RESEARCH DURING THE YEAR $(\mathrm{M} \pm \mathrm{M})$

\begin{tabular}{|l|l|l|l|}
\hline Indicators & Step I & Step IV & \multicolumn{1}{|c|}{$\begin{array}{c}\Delta \% \\
(\text { Steps I-IV })\end{array}$} \\
\hline $\begin{array}{l}\mathrm{Aps} \\
(\mathrm{mm} \mathrm{Hg})\end{array}$ & $108,19 \pm 10,19$ & $103,10 \pm 9,99$ & $-4,67 * *$ \\
\hline $\begin{array}{l}\mathrm{APd} \\
(\mathrm{mm} \mathrm{Hg})\end{array}$ & $76,16 \pm 8,19$ & $76,30 \pm 10,76$ & 0,18 \\
\hline $\begin{array}{l}\text { Heart rate } \\
\left(\mathrm{min}^{-1}\right)\end{array}$ & $83,51 \pm 6,29$ & $82,46 \pm 11,67$ & $-2,58^{*}$ \\
\hline $\begin{array}{l}\mathrm{AP} \\
(\text { conv.un. })\end{array}$ & $110,9 \pm 5,19$ & $109,5 \pm 5,81$ & $-1,26^{*}$ \\
\hline $\begin{array}{l}\text { VKI } \\
(\text { conv. un })\end{array}$ & $0,91 \pm 0,03$ & $0.92 \pm 0,02$ & $-1,09^{*}$ \\
\hline Notes: see table 1. & \multicolumn{2}{|l}{} \\
\hline
\end{tabular}

The difference in systolic pressure was $2,09 \%(\mathrm{p}<0,01)$, in diastolic it was $13,3 \%(\mathrm{p}<0,05)$, in heart rate it was $15,28 \%$ $(\mathrm{p}<0,05)$, in VKI it was $5,88 \%(\mathrm{p}<0,001)$ and in AP it was $12,9 \%(\mathrm{p}<0,05)$.

In general, it can be concluded that the state of tension of neurohumoral mechanisms of self-regulation remains in the control group of the children throughout the period of research, accompanied by the mobilization of functional resources and instability of homeostasis indicators, which leads to a decrease in the stock of functional reserves and narrows the range of possible adaptive reactions significantly.

Because of the regular Taoist health gymnastics "Qigong", there is an increase in the intensity of the influence of the autonomic nervous system on systemic circulation in the main group of the children, as well as a decrease in metabolic and humoral effects on the heart.

To identify the features of the external breathing system reactions to the action of regular Taoist health gymnastics "Qigong" we analyzed the data obtained for each of the selected groups. 
TABLE IV. CHANGES OF SPIROMETRY PARAMETERS IN CHILDREN OF THE CONTROL GROUP $(\mathrm{N}=10)$

\begin{tabular}{|l|c|c|c|c|}
\hline Indicators & Step I & Step IV & $\begin{array}{c}\Delta \% \\
\left(\begin{array}{c}\text { Steps I- } \\
\text { IV })\end{array}\right.\end{array}$ & $\boldsymbol{P}$ \\
\hline $\begin{array}{l}\text { RR } \\
\text { (breaths/min) }\end{array}$ & $\begin{array}{c}22,32 \pm \\
3,16\end{array}$ & $\begin{array}{c}20,32 \pm \\
3,44\end{array}$ & $-8,96$ & $\mathbf{0 , 0 0 0 1}$ \\
\hline $\begin{array}{l}\mathrm{RV} \\
(\mathrm{ml})\end{array}$ & $\begin{array}{c}250,35 \pm \\
68,84\end{array}$ & $\begin{array}{c}255,37 \pm \\
46,43\end{array}$ & 2,00 & 0,8676 \\
\hline $\begin{array}{l}\text { MBV } \\
(\mathrm{ml} / \mathrm{min})\end{array}$ & $\begin{array}{c}5587,81 \pm \\
380,2\end{array}$ & $\begin{array}{c}5189,11 \pm \\
298,64\end{array}$ & $-7,13$ & 0,4047 \\
\hline $\begin{array}{l}\text { VC } \\
\text { (ml) }\end{array}$ & $\begin{array}{c}2174,42 \pm \\
613,0\end{array}$ & $\begin{array}{c}2218,83 \pm \\
535,82\end{array}$ & 2,04 & 0,4047 \\
\hline $\begin{array}{l}\text { Heart Rate } \\
\text { (beats/min) }\end{array}$ & $\begin{array}{c}83,51 \pm \\
6,29\end{array}$ & $\begin{array}{c}82,46 \pm \\
5,67\end{array}$ & $-1,25$ & $\mathbf{0 , 0 4 2 5}$ \\
\hline $\begin{array}{l}\text { HI } \\
\text { (\%) }\end{array}$ & $\begin{array}{c}3,74 \pm \\
0,72\end{array}$ & $\begin{array}{c}4,05 \pm \\
0,51\end{array}$ & 8,28 & $\mathbf{0 , 0 0 0 1}$ \\
\hline
\end{tabular}

Notes: here and further RR is respiration rate; RV is respiratory volume, MBV means minute breath volume, VC stands for vital capacity of lungs, $\mathrm{HI}$ is the Hildebrant index and $\Delta \%$ corresponds to the difference between "before" and "after" the experiment as a percentage.

The people of the control group before and after the experiment had the following changes: RR increases by $13,8 \%$ ( $\mathrm{p}<0,001)$ compared to the baseline, heart rate decreased by $1,25 \%(\mathrm{p}<0,05)$ and HI increased by $8,28 \%(\mathrm{p}<0,001)$ (table 4 ). These changes indicate a lack of effectiveness of school physical education to improve the function of the respiratory system.

Analyzing the indicators of the people from the experiment of the main group at the first step, it should be noted that all the studied parameters are within the physiological norm, but some of them are close to the upper or lower limits of the norm [14].

As it is shown in the table $5, \mathrm{RR}$ is equal to $21,92 \pm 2,03$ breaths/min, $\mathrm{RV}$ is equal to $200,05 \pm 38,61 \mathrm{ml}, \mathrm{MBV}$ is equal to $4385,09 \pm 220,32 \mathrm{ml} / \mathrm{min}, \mathrm{VC}$ is equal to $2021,31 \pm 423,01 \mathrm{ml}$ and $\mathrm{HI}$ is equal to $4,05 \pm 0,32 \%$. After three months of gymnastics "Qigong" only RR improved significantly by $8,66 \%(\mathrm{p}<0,05)$ and became equal to $20,02 \pm 3,03$ breaths $/ \mathrm{min}$.

After six months of training (step II), four of the six indicators have changed: RR decreased by $9,84 \%(\mathrm{p}<0,05)$ and became equal to $18,05 \pm 2,03$ breaths/min, MBV increased by $3,06 \% \quad(p<0,05)$ and became equal to $4519,53 \pm 105,36$ $\mathrm{ml} / \mathrm{min}$, heart rate decreased by $6,08 \%(\mathrm{p}<0,01)$ and became equal to $84,96 \pm 11,03\left(\mathrm{~min}^{-1}\right)$, HI increased by $0,89 \%(\mathrm{p}<0,01)$ and became equal to $4,59 \pm 0,38 \%$.

TABLE V. CHANGES IN SPIROMETRY OF THE CHILDREN OF THE MAIN GROUP $(\mathrm{N}=24)$

\begin{tabular}{|l|c|c|c|c|}
\hline \multicolumn{1}{|c|}{ Indicators } & Step I & Step II & Step III & Step IV \\
\hline RR & $21,92 \pm$ & $20,02 \pm$ & $18,05 \pm$ & $16,04 \pm$ \\
(breaths/min) & 2,03 & 3,03 & 2,03 & 1,07 \\
\hline RV & $200,05 \pm$ & $210,38 \pm$ & $240,39 \pm$ & $260,15 \pm$ \\
(ml) & 38,61 & 21,21 & 21,07 & 25,24 \\
\hline MBV & $4385,09 \pm$ & $4211,80 \pm$ & $4519,53 \pm$ & $4814,40 \pm$ \\
(ml/min) & 220,32 & 110,45 & 105,36 & 101,35 \\
\hline VC & $2021,31 \pm$ & $2035,21 \pm$ & 2050,62 & $2120,06 \pm$ \\
(ml) & 423,01 & 328,31 & $\pm 101,01$ & 90,02 \\
\hline Heart Rate & $98,71 \pm$ & $91,17 \pm$ & 84,96 & $81,08 \pm$ \\
(beats/min) & 8,0 & 9,51 & $\pm 11,03$ & 9,02 \\
\hline HI & $4,05 \pm$ & $4,55 \pm$ & $4,59 \pm$ & $5,05 \pm$ \\
(\%) & 0,32 & 0,21 & 0,38 & 0,30 \\
\hline
\end{tabular}

The most pronounced changes in the function of the respiratory system were noted after a year of continuous training of Taoist health gymnastics "Qigong". All the studied indicators had significant differences. So, RR and heart rate decreased by $26,82 \%(\mathrm{p}<0,01)$ and $17,86 \%(\mathrm{p}<0,05), \mathrm{RV}$ increased by $30,04 \%(\mathrm{p}<0,01)$ and became equal to $260,15 \pm 25,24 \mathrm{ml}$., MBV increased by $9,79 \%(\mathrm{p}<0,01)$ and became equal to $4814,40 \pm 101,35 \mathrm{ml} / \mathrm{min}$, VC changed slightly (by $4,88 \%(\mathrm{p}<0,05))$, HI, reflecting the conjugation of the cardio-respiratory system improved by $24,69 \%(\mathrm{p}<0,05)$ and became equal to $5,05 \pm 0,30 \%$ (table 5 , table 6 ).

TABLE VI. CHANGES IN SPIROMETRY OF THE CHILDREN OF THE MAIN GROUP $(\mathrm{N}=24)$ AT ALL STEPS OF THE STUDY DURING THE CALENDAR YEAR $(\mathrm{M} \pm \mathrm{M})$

\begin{tabular}{|l|c|c|c|c|}
\hline \multicolumn{1}{|c|}{ Indicators } & $\begin{array}{c}\Delta \% \\
(\text { Steps I-II) }\end{array}$ & $\begin{array}{c}\Delta \% \\
(\text { Steps II- } \\
\text { III })\end{array}$ & $\begin{array}{c}\Delta \% \\
(\text { Steps III- } \\
\text { IV })\end{array}$ & $\begin{array}{c}\Delta \% \\
(\text { Steps I- } \\
\text { IV })\end{array}$ \\
\hline $\begin{array}{l}\text { RR } \\
\text { (breaths/min) }\end{array}$ & $-8,66^{*}$ & $-9,84 *$ & $-11,13 *$ & $-26,84^{* * *}$ \\
\hline $\begin{array}{l}\mathrm{RV} \\
(\mathrm{ml})\end{array}$ & 5,16 & 14,26 & $8,21 * *$ & $30,04 *$ \\
\hline $\begin{array}{l}\mathrm{MBV} \\
(\mathrm{ml} / \mathrm{min})\end{array}$ & 4,11 & $3,06 *$ & $3,63 *$ & $9,79 * *$ \\
\hline $\begin{array}{l}\mathrm{VC} \\
(\mathrm{ml})\end{array}$ & 0,68 & 0,75 & 3,38 & $4,88 *$ \\
\hline $\begin{array}{l}\text { Heart Rate } \\
(\mathrm{beats} / \mathrm{min})\end{array}$ & $-7,13 * *$ & $-6,08$ & $-4,74 * *$ & $-17,86 *$ \\
\hline $\begin{array}{l}\text { HI } \\
(\%)\end{array}$ & 12,3 & $0,89 *$ & $10,02 * * *$ & $24,69 *$ \\
\hline
\end{tabular}

The differences in the relative spirometry indices of the children of the control and main groups was obtained before and after the experiment (steps I - IV) are presented in table 4, table 6 .

So, RR is different by $17,86 \%$ ( $\mathrm{p}<0,05-0,01)$; RV, by $28,04 \%(\mathrm{p}<0,05)$; MBV, by $2,66 \%(\mathrm{p}<0,05)$; VC, by $2,84 \%$ $(\mathrm{p}<0,05)$; and HI, by $23,44 \%(\mathrm{p}<0,05)$.

\section{DISCUSSION}

To summarize the research, we should say that breathing exercises in gymnastics "Qigong" are based on the use of different methods of free and rhythmic breathing [14]. For example, diaphragmatic breathing improves pulmonary ventilation and massage of internal organs due to movements of the diaphragm and activation of metabolic processes. The breath delay used in our program is a deliberately prolonged phase of inhalation or exhalation, which allows to extract the maximum amount of oxygen from the air in the alveoli, which increases the efficiency of breathing in general [14]. During breath holding there is the inhibitory-relaxation functional system of the body's protection from extreme effects of qualitatively different, but sufficiently strong stimuli (adaptogenic factors) accompanied by tissue hypoxia [17]. The principle of operation of this system is that under the influence of hypoxia and disturbances in the relationship of the most important homeostatic constants (oxygen and carbon dioxide) in the central nervous system, inhibitory processes are activated, and on the periphery the rate of arbitrary relaxation of all skeletal muscles increases sharply (sometimes by $70 \%$ ). 
[8] H.J. Greten, "Understanding TCM. The Fundamentals of Chinese Medicine", Part I, Heidelberg School, Heidelberg, Germany, 2013.

This is a possible mechanism for improving the functioning of the respiratory muscles and the respiratory system as a whole.

\section{CONCLUSIONS}

The change in the studied parameters indicates an improvement in the regulatory mechanisms of all parts of the cardio-respiratory system to ensure its adaptation to physical activity. Lessons of health gymnastics "Qigong" have a controlled effect on the physiological systems of the body and the emotional sphere involved, which is manifested by urgent and cumulative effects with positive consequences.

\section{References}

[1] N.Yu. Tarabrina, "Psychophysiological assessment of law students health”, Theory and Practice of Physical Culture, 2015, № 1, pp. 52-54.

[2] The Demographic Yearbook of Russia, Statistical Handbook, Rosstat, 2017, 263 p.

[3] Jody L. Riskowski, Rania Almeheyawi, "Effects of Tai Chi and Qigong in Children and Adolescents: A Systematic Review of Trials", Adolescent Res Rev, 2019, vol. 4, pp. 73-91.

[4] T.V. Levchenkova, Yong-Mei Wang, "National gymnastics disciplines in the program on physical culture schools of China (the example of Qigong)", Physical culture: upbringing, education, training, 2015, vol. 2, pp. 53-55.

[5] V.P. Lopes, J.A. Maia, L.P. Rodrigues, R. Malina, "Motor coordination, physical activity and fitness as predictors of longitudinal change in adiposity during childhood". European Jounral of Sport Science, 2012, vol. 12(4), pp. 384-391.

[6] N.Yu. Tarabrina, "Health correction of bodily condition of students with functional violations neck-thoracal to the department of spine", Pedagogics, psychology, medical-biological problems of physical training and sports, 2010, vol. 8, pp. 86-89.

[7] C. Witt, M. Becker, K. Bandelin, R. Soellner, S.N. Willich, "Qigong for schoolchildren: a pilot study", Journal of Alternative and Complementary Medicine, 2005, vol. 11(1), pp. 41-47.
[9] H.J. Greten, "Understanding TCM. The Fundamentals of Chinese Medicine”, Part II, Heidelberg School, Heidelberg, Germany, 2013.

[10] Kiew Kit Wong, Chi Kung for health and vitality, Vermilion, London, 1997.

[11] H.J. Greten, Y. Xia, G.H. Ding, G.C. Wu, (eds.), Chinese medicine as a model of system biology - diagnosis as the foundation of acupoint selection. In Current Research in Acupuncture. Research Monograph, Springer, Berlin, Germany, 2012.

[12] Claudia Witt, Matthias Becker, Karin Bandelin, Renate Soellner, Stefan N. Willich, "Qigong for Schoolchildren: A Pilot Study", The Journal of Alternative and Complementary Medicine, 2005, vol. 11(1), pp. 41-47.

[13] C. Lan, SW. Chou, SY. Chen, JS. Lai, MK. Wong, "The aerobic capacity and ventilatory efficiency during exercise in Qigong and Tai Chi Chuan practitioners", The American Journal of Chinese Medicine, 2004, vol. 32(1), pp. 141-150.

[14] T.C. Koh, "Qigong - Chinese Breathing Exercise", The American Journal of Chinese Medicine, 1982, vol. 10(1-4), pp. 86-91.

[15] Luís Carlos Matos, Cláudia Maria Sousa, Mário Gonçalves, Joaquim Gabriel, Jorge Machado, Henry Johannes Greten Qigong as a Traditional Vegetative Biofeedback Therapy: Long-Term Conditioning of Physiological Mind-Body Effects, BioMed Research International, 2015, Article ID 531789, 6 p.

[16] N.Yu. Tarabrina, E.Yu. Grabovskaya, V.A. Tarabrina, A.R. Abduramamov, "Manifestation of the main indicators of the central cardiohemodynamics in wrestlers of different qualification", Scientific notes of Taurida National V.I. Vernadsky University. Series: Biology, Chemistry, 2018, vol. 4 (70), №1, pp. 92-103.

[17] N.Yu. Tarabrina, "Muscle relaxation technique to correct thoracocervical scoliotic disorders in athletes", Theory and Practice of Physical Culture, 2016, № 4, pp. 30-32.

[18] E.I. Mikhailova, H.G. Mikhailov, E.B. Derevleva, M.A. Kaimin, O.V. Kudryavtseva, "Gymnatics in the content of schoolchildren physical upbrining", Russian Journal of Physical Education and Sport, 2018, vol. 13, No. 2, pp. 129-136. DOI 10.14526/02_2018_321 